\title{
Common Terminal-sensitive Submunition with Function of Blockade and Control Jiaoying Yang ${ }^{1, \mathrm{a}}$, Guanglin $\mathrm{He}^{1, \mathrm{~b}}$ and Zhan Zhang ${ }^{1, \mathrm{c}}$ \\ ${ }^{1}$ School of Mechatronical Engineering, Beijing Institute of Technology University, Beijing 100081, China; \\ ayangjiaoying0115@163.com, he8507@aliyun.com, cpeakcanghai@live.com
}

Keywords: common, terminal-sensitive, blockade and control, developing trends.

\begin{abstract}
Terminal-sensitive ammunition based on sensitive detection technology, as well as ammunition of blockade and control based on ad hoc network, homing technology etc. are both smart submunition with high attention in recent years. Based on the analysis of the technical background and development of the two kinds of ammunitions, a new-type ammunition which combines functions of terminal-sensitive as well as blockade and control is presented. Some key technologies are discussed and the developing trends of smart munition is prospected.
\end{abstract}

\section{Introduction}

\subsection{Terminal-sensitive Ammunition and Blocked-zone Ammunition.}

Terminal sensitive submunition is one of smart munition that can detect the presence of target at the end of trajectory, and make the warhead explosion toward the goal direction ,has apply a variety of advanced technology to the field of cargo projectile. It can be launched from a variety of platforms, mainly used for autonomous attack armored target top armor[1].

Blocked-zone ammunition used to impose a blockade on the combat zone, attack enemy aircraft, tanks, armored vehicles, ships and equipment and effectives which into the blocked area.In order to delay the enemy fighters, slowing the build-up of troops and deployment, leads to the loss of the war capability, so as to gain time for allied, master the wartime purpose of the initiative[2].

According to operational objectives, blocked-zone ammunition can be divided into damage / killer type blocked-zone ammunition. The former is used against armored vehicles, equipment, personnel and other targets. Typical equipment such as HB-876 airport blocked ammunition, anti -tank mines and other sub MIFF; the latter hindering enemy combat missions through the destruction of the airport runway, bridge, and highway. Typical equipment such as BLU-106/B anti runway bomb, anti-runway munitions SG-357.

\subsection{Demand Analysis.}

In the Gulf War, the Afghanistan war and the Iraq war, the US army Use a large amount of shrapnel, left a huge amount of blind fire double use bullets, In desert storm left blind fire at least 170 thousand bullets, led to a large number of civilian casualties, and condemned by the international community[3]. Currently, the research on reconnaissance and strike of blocked-zone ammunition, self-networking, self-repair and so on, has achieved some initial results. Such as XM1100 intelligent minefield defense of the United States, can cover the target area of 2.56 square kilometer after self-networking. Meanwhile, Germany SMArt155 represented by high-performance sensitivity Projectile has proved such ammunition has huge economic damage and performance advantages.
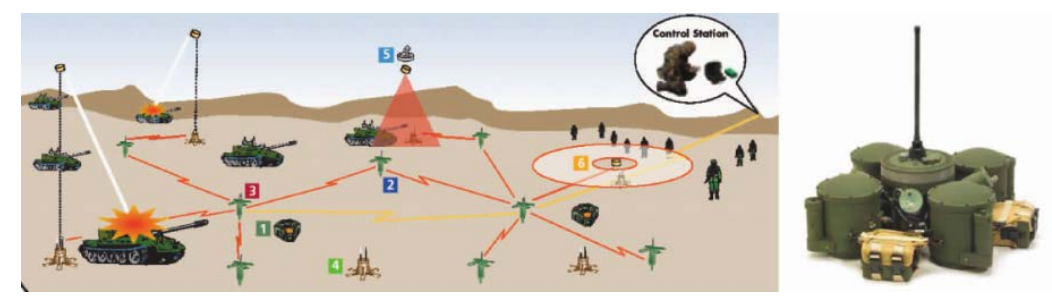

Fig.1 XM1100 "scorpion" intelligent ammunition system 


\section{Research Status}

\subsection{Advanced Terminal Sensitive Projectile Development Situation.}

Since 60's of last century, many countries have carried out the research on the technology of terminal sensitive projectile. Among them, the United States SADARM sensitive bomb, Germany's SMArt155 and Sweden and France developed the BONUS are most representative.

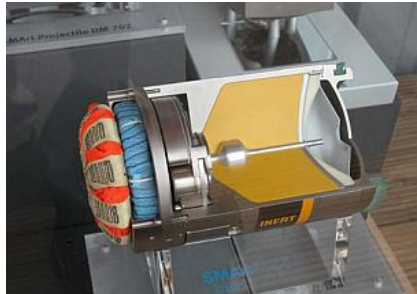

Fig.2 SMArt 155

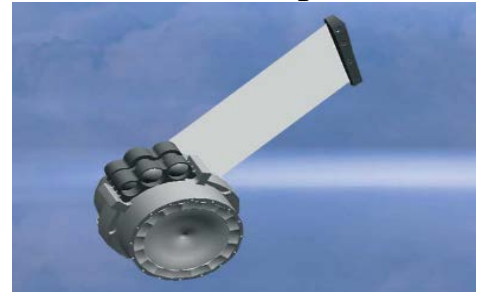

Fig.3 Common Smart Submunition

Textron Systems of the United States began producing BLU-108 intelligent anti-armor ammunition in 1992, which contained 4 Skeet terminal sensitive ammunition. Table 1 shows the comparison of a variety of terminal sensitive projectiles.

Table 1 Comparative characteristics of different sensitivity Projectile

\begin{tabular}{|c|c|c|c|}
\hline name feature & Sensor type & Armor ability & Advantage \\
\hline $\begin{array}{l}\text { GermanyDM702 } \\
\text { (SMArt) }\end{array}$ & $\begin{array}{l}\text { Composite sensor: } \\
\text { Infrared detector, }\end{array}$ & $108 \mathrm{~mm}$ & $\begin{array}{l}\text { powerful anti-jamming } \\
\text { performance; }\end{array}$ \\
\hline $\begin{array}{l}\text { Sweden/France } \\
\text { BONUS }\end{array}$ & $\begin{array}{l}\text { active/passive } \\
\text { millimeter wave } \\
\text { composite sensor }\end{array}$ & $\begin{array}{l}\text { 150mheight } \\
120 \sim 130 \mathrm{~mm}\end{array}$ & $\begin{array}{l}\text { longest-range; } \\
\text { no parachute, less affected by } \\
\text { wind }\end{array}$ \\
\hline U.S.A “Skeet” & $\begin{array}{l}\text { Laser / infrared } \\
\text { dual mode sensor }\end{array}$ & $80 \mathrm{~mm}$ & $\begin{array}{l}\text { standardization design for } \\
\text { appearance and interface } \\
\text { ability to determine the targets }\end{array}$ \\
\hline U.S.A CSS & $\begin{array}{l}\text { Passive infrared / } \\
\text { laser radar dual } \\
\text { mode detector }\end{array}$ & $80 \mathrm{~mm}$ & $\begin{array}{l}\text { Samara Wing; } \\
\text { self-destruction, } \\
\text { self-neutralization }\end{array}$ \\
\hline
\end{tabular}

\subsection{Development and Trend of Blockade Control Ammunition.}

With the rise of the air force, the submunition has developed to use air force covering type delivery. Recently, the development of self-networking technology, sensor detection technology, passive location technology and homing technology, has provided a technical approach for intelligential, controllable and multifunctional of blockade control ammunition. At present, the main development form of the blockade control ammunitions are the following:

\section{(1) Intelligent Minefield}

In 2000 2003, the Defense Advanced Research Projects Agency put forward the "self-repairing minefield" plan. Each blockade mine has both wireless communication and self-organizing network unit, can quickly constitutes a wireless ad hoc networks.

In order to assort the "self-healing minefield" plan, the US Sandia National Laboratories developed an Intelligent Motor Land Mine (IMLM) system, improved anti-tank mine, the IMLM system can automatically detect whether there is path was opened in the minefield, and then decide what needs to be moved to block the pathway, and then reconfigure the minefields, closed the path.

\section{(2) Ground Sensor Monitoring System}

By combining the application of a variety of sensors to achieve a sealed off area of intelligence, surveillance, reconnaissance, combat integration, not only can continuously get battlefield situation and quick strike capture, but also can be precisely controlled the combined effect of lethal and nonlethal of ammunition. Through the realization of computer remote communication of multiple data links, we can achieve the purpose of remote monitoring.

\section{(3) Special Blockade Control Ammunition}

This ammunition is mainly used to destroy power supply system, communication systems and other equipment and facilities, or for non-lethal incapacitating personnel, equipment, and 
ammunition, which belongs to soft killing ammunition. For example, the US military air strikes against Yugoslavia used BLU-114 / B, resulting in Yugoslavia for 70\% power off area. An SUU-66 / B dispenser can carry 200 BLU-114 / B, can also be used JSOW stand-off dispenser to serve.

This new blockade control ammunition system, which combined information acquisition, transmission, reception and attack as a whole set, can be widely used for blocking enemy airports, harbours, caves, transportation hub, against enemy armor cluster, high tech equipment positions, achieved the purpose of block specific goals and has good application prospect in military.

\section{Key Technologies}

\subsection{Composite Detection Technology.}

The detection and recognition of moving target signal is the main battlefield combat missions as bullets. Whether the target can be detected quickly, and the implementation of accurate and reliable discrimination on target properties, is an important indicator to test the performance of the system.

The Germany DM702 terminal sensitive ammunition using infrared detectors, 94GHz mm wave radar and millimeter wave radiometer composite sensor, has a strong anti-interference ability, low false alarm rate.

Thus, single sensor is not suitable for detect and target recognition in the complex battlefield environment, typically using a combination of two or more than two kinds of system of sensors, complement each other. It is necessary to upgrade and expand our existing sensitive detection technology, in order to achieve effective integration of terminal sensitive and blockade control function, adding magnetic sensors, seismic sensors, and some composite detection technology to the blockade control ammunition, as the precondition that the aerodynamic shape of the projectile will not be affected.

\subsection{Attitude Control Technology.}

The attitude control of terminal sensitive ammunition can be roughly divided into two stages, one is the steady state scanning during the fall of the bullet; the two is the attitude centralize of the ammunition when landing.

\section{(1) Stable Scanning Technology}

States from the current development situation of view, the formation of the stable scanning motion of the bullet mainly has two kinds of technical methods:

Table 2 Comparison of the steady state scanning mode

\begin{tabular}{|c|c|c|c|}
\hline feature & example & advantage & disadvantage \\
\hline $\begin{array}{l}\text { using } \\
\text { parachute }\end{array}$ & $\begin{array}{l}\text { U.S.A } \\
\text { SADARM } \\
\text { Germany } \\
\text { SMArt155 }\end{array}$ & $\begin{array}{l}\text { speed of rotation is slow, } \\
\text { easy to implement } \\
\text { electronic component }\end{array}$ & $\begin{array}{l}\text { parachute drop rate is } \\
\text { low, vulnerable to the } \\
\text { enemy to fight back; }\end{array}$ \\
\hline
\end{tabular}

$\begin{array}{lll}\begin{array}{l}\text { using wing } \\ \text { structure }\end{array} & \begin{array}{c}\text { Sweden/France } \\ \text { BONUS }\end{array} & \begin{array}{l}\text { Reduce the influence of falling fast, difficult to } \\ \text { wind } \\ \text { interference }\end{array}\end{array}$

Stable Scanning aims to enable projectile approximate vertical drop uniformly, while playing around a vertical axis of the shaft and a fixed angle uniform rotation. The scanning with parachute greatly affected the terminal sensitive projectile overall operational effect, while scanning without parachute has the advantages of small size, falling speed high, flight time is short, and little affected by wind.

The U.S.A Common Smart Submunition using a known as "Samara wing "structure, for the submunition stable scanning. The structure of the main wing contains a leading edge and a trailing edge, the ailerons also have the leading and trailing edge, which are connected by a pivot, near the trailing edge of the main wing, and separated by a gap. There are two modes of operation, one is high-speed mode of vertical drop, in this mode Samara wing does not rotate and keep the high speed. Another is called low speed rotation mode which the effective load close to ground. 


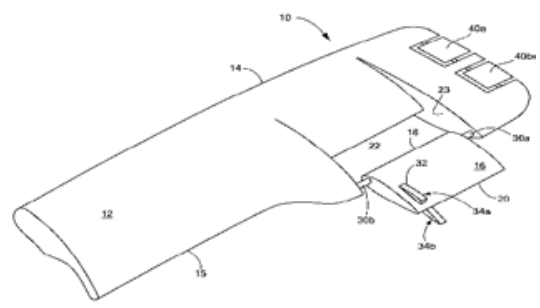

Fig. 4 Structure of "Samara wing"

\section{(2) Landing Centralize Technology}

The landing attitude of the blockade control ammunition decides whether it can effectively acquire the battlefield information and data transfer. On the one hand, only the bullets keep upright state can ensure the detected target range, speed and reliable information; on the other hand, antenna needs to remain upright state to keep smooth communication between internal network and the rear ground receiving system.

\subsection{Other Key Technologies}

\section{(1) Bullet Group Wireless Networking Technology}

Applied wireless networking technology in system, the single worked node combined into a practical wireless network according to certain protocol method, to a greater extent played a single bullet function. When a node failure or a new node is added, it is possible to re-networking, to adjust the overall detection reliability, give full play to its advantages in resources

\section{(2) Anti High-overload Technology}

In order to enable the bullet to withstand the huge overload of the launch, need to take reasonable anti-overload measures, such as using high-strength material parts, additional buffer seismic isolation device, improve the structure of distribution.

\section{(3) Long Distance Communication Technology}

In order to achieve the information transmission between the target area and command post , under the condition of long Distance, shielding, non-visibility, we should take optimized structural design, and other means to increase the transmission power.

\section{Conclusion}

The common terminal-sensitive submunition with function of blockade and control is a new type of smart munitions, has the advantages of both terminal sensitive submunition and blockade control submunition, and make up a single defect each function with high flexibility, cost-effectiveness ratio, good accuracy, adaptability and other advantages. Because it is not easily affected by the weather, it can achieve a better combat effectiveness in a variety of operational environments, has important significance for improving the ability of weapon system in our country and to promote the development of intelligence, standardization and general of ammunition.

\section{Reference}

[1]. Zhao Yuqing, Niu Xiaomin, and Wang Xiaobo. The Development Present and Trend of Intelligent Submunitions. GUIDANCE\&FUZE. Vol.33(2012),No.4,p.13-19.

[2].Yin Ximei, Wang Zhancao. Overview of Ground Blocked Zong Ammunition. Ordnance Industry Automation. Vol.33(2014), No.7,p79-82.

[3]. Zhao Yuqing, Sun Qiang. Journal of Detection\&Control. Vol.35(2013), No.3, p1-7.

[4].Chen Dong, Zhang Yunbing, and Liu Chuang. An Artillery Blockade and Control Ammunition and Its Key Technique. Ship Electronic Engineering. Vol.34(2014), No.3, p1-p3

[5]. Yu Jiyan: Research on the Overall and Detection System of the Blocked Mine Projectile(Master's degree, Nanjing University of Science and Technology, China 2013) 
[6].Zhang Nan, Jiao Guotai, Zhang Ruigang and Ma Wenzhong. Research on the location of intelligent blocking mine. Journal of Projectiles, Rockets, Missiles and Guidance.Vol.28, No.1, p135-137.

[7]. Timothy M. Barrows. SAMARA WING: U.S. Patent 20100324754 A1[P]. 2010-12-23.

[8].Yuan Ping, Cheng Xiang, and Zhang HE. Research on intelligent minefield of wireless communication network. Journal of Projectiles, Rockets, Missiles and Guidance. Vol.28(2003),No.2,p43-45.

[9].Wang Shuguang: Research on key technology of sensitive projectile weapon system (doctor's degree, Army Academy, China 2009) 